\title{
DOLERSE, QUE SIEMPRE ES ESCRIBIR DE OTRA MANERA
}

\author{
Dolerse. Textos desde un país herido \\ Cristina Rivera Garza \\ Surplus ediciones, México, 2015 \\ 181 pàgs. 23 euros / \$250 MXN
}

$\mathrm{F}$

rente al enmudecimiento que adviene a quienes son testigos integrales del horror, Cristina Rivera Garza propone articular la desarticulación muda a través de «la necesidad política de decir "tú me dueles", de recorrer mi historia contigo, que eres mi país, desde la perspectiva única, aunque generalizada, de los que nos dolemos» (Rivera, 2015, p. 14). Dolerse, textos desde un país herido es una propuesta política que se formula desde el lugar de la escritura para sobrevivir los tiempos y lugares del horror.

El libro se compone de una serie de textos escritos en distintos momentos durante los últimos diez años, no pretende componer una unidad, cada uno de ellos responde a diferentes episodios del espectáculo del horrorismo contemporáneo en México. Valiéndose de relatos, testimonios, entrevistas, indagaciones históricas y

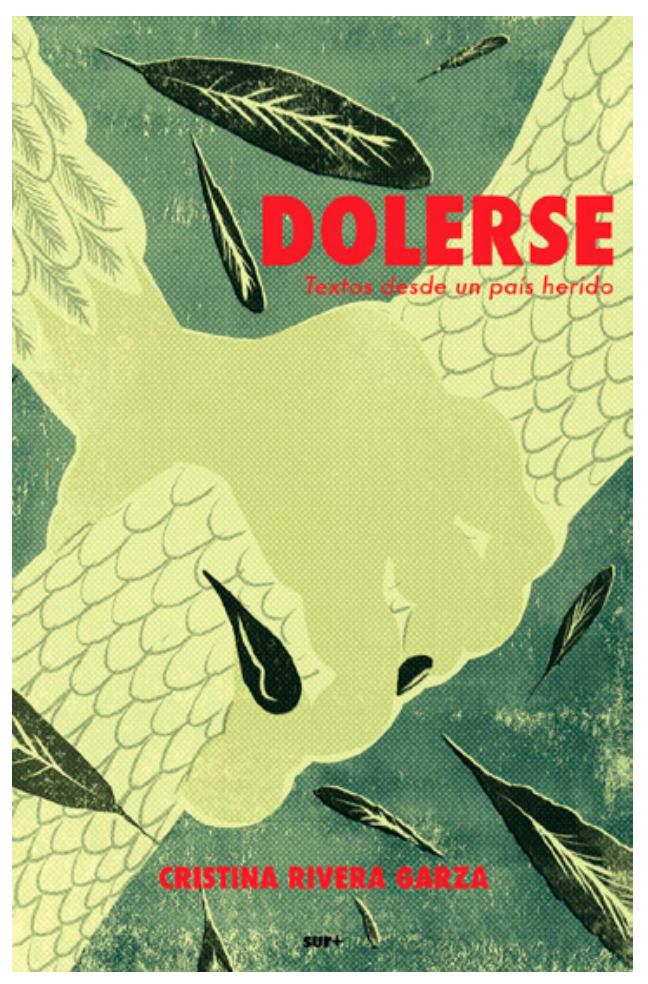

Dolerse, textos desde un país herido es una propuesta política que se formula desde el lugar de la escritura para sobrevivir los tiempos y lugares del horror.

perspectivas teóricas, genera escritos con fuerza y pertinencia estética que fabrican presente. 
Los textos se enfrentan con de las expresiones del dolor y de interrogantes que persiguen a todo reconocer en ellas la vulnerabilidad aquél que ha experimentado lo que se vive en México, ¿cómo nombrar, tratar, enfrentar, entender, si es que es posible, el horror y la violencia que acontece? ¿Cómo escribir o dar cuenta de lo que el cuerpo dolido dice titubeante de manera entrecortada?

Como se preguntaría Primo Levy, ¿de qué manera afrontar la aporía sobre el testigo integral que ya no puede testimoniar? El que se horroriza, escribe Rivera Garza, retomando a Adriana Cavarero (2009), «separa los labios e, incapaz de pronunciar palabra alguna, incapaz de articular lingüísticamente la desarticulación que llena la mirada, muerde, así, el aire» (Rivera, 2015, p.10).

La autora propone la afirmación del dolor como la posibilidad de transitar la parálisis producida por el horror. El dolor, nos dice, «permite articular una experiencia inenarrable como una crítica intrínseca contra las condiciones que lo hicieron posible en primera instancia» (Rivera, 2015, p.13). De ahí, la importancia de condolerse, de generar conexiones íntimas a partir propia y del otro.

Los textos dolientes son un ejercicio de disenso, son parte de la reconfiguración de lo que se puede ver, decir y pensar. Son un diálogo interno «no piden conmiseración; no están sujetos al mercado de la lástima. No tratan ni de tomar la voz ni de dar la voz a las múltiples voces que existen, de hecho, por sí mismas» (Rivera, 2015, p.16).

Disputan las formas consuetudinarias de narrar, representar $\mathrm{y}$ experimentar la guerra contra el narcotráfico. Más allá de los enunciados y consignas que justifican o reclaman, este trabajo se propone atravesarlo todo para poner en primer plano la experiencia del dolor. Es un despliegue de eso que suele llamarse guerra en sus expresiones encarnadas, donde la guerra ya no puede ser simplemente guerra, sino guerra vivida. 
La distinción que hace Rancière (1996) entre policía y política, ${ }^{1}$ ayuda a pensar que la posibilidad de una reconfiguración de lo que se puede ver y decir se da cuando hay un corrimiento del lugar asignado. Desplazarse de las disposiciones del horror para reconocer el dolor como una verificación del daño a la igualdad y una afirmación como la parte de los sin parte, es, en sus propios términos, un momento político.

Esta perspectiva del dolor retoma la propuesta de Judith Butler en torno a la vulnerabilidad como condición humana, en la cual el nosotros como pronombre colectivo es condición del yo, y con ello, nos dice Rivera Garza, «hay un acuerdo más que tácito con Emmanuel Levinas: en un ser para otro, en un ser en tanto otro» (2015, p. 156); de ahí que el duelo tanto público como privado, sea un acto de reconocimiento de la vulnerabilidad humana y un llamado al cuidado del otro; acción que se

1 Llama policía a los mecanismos que ordenan y distribuyen las partes de la comunidad y política al momento en que se suspende dicho orden para verificar el daño a la igualdad y reconfigurar el ordenamiento por medio de la irrupción de la parte de los sin parte. contrapone directamente a la violencia y el horror.

Los textos también esbozan el sustento de un horror vertiginoso: la lógica de la ganancia por encima de todo, es decir, una red de conexiones producidas por la práctica articulatoria del capital que ha estrechado los vínculos entre el Estado, la criminalidad y el empresariado global. El Estado sin entrañas, como ha nombrado Rivera Garza a los Estados sumidos en la mercantilización de la vida, produce el cuerpo desentrañado, ese interior que se vuelve exterior - pedazos de torso, piernas, pies-, donde «los cuerpos de los ciudadanos además de vulnerables, se volvieron inermes» (Rivera, 2015, p.12).

Dolerse. Textos desde un país herido no compone un tratado sobre el dolor; es, si se quiere, la puesta en práctica, la experimentación del «Yo me duelo» de Cristina: la afirmación escrita de un dolor constitutivo. Se trata de una exposición, pero también, de un desdoblamiento del yo. Dolerse se ha extendido hasta encontrar un lugar común, un encuentro. Escritores de México, España y Estados Unidos han respondido al llamado, han hecho 
posible una segunda publicación, Rivera, C. (2015), Dolerse. Textos desuna multiplicación de la primera, ya no se trata de «Dolerse» sino de de un país herido, Surplus, México.

«Con/dolerse». ${ }^{2}$

Ana Paula Felix

Facultad de Ciencias Políticas y Sociales, Universidad Nacional Autónoma de México, Ciudad de México.

\section{Luis Gómez Negrete}

Facultad de Ciencias Políticas y Sociales, Universidad Nacional Autónoma de México, Ciudad de México.

\section{Referencias}

Butler, J. (2007), Vida precaria. El poder del duelo y la violencia, Paidós, España.

Cavarero, A. (2009), Horrorismo. Nombrando la violencia contemporánea, Anthropos y UAM Iztapalapa, España.

Rancière, J. (1996), El desacuerdo. Política y filosofia, Nueva Visión, Buenos Aires.

2 Esta segunda edición de Dolerse. Textos desde un país herido lleva consigo otra publicación llamada «Con/dolerse» en la cual quince autores dialogan a partir de sus propios textos dolientes. 